\title{
Guidance on Gene Replacement Therapy in Spinal Muscular Atrophy: A Canadian Perspective
}

\author{
Maryam Oskoui (D), Hernan Gonorazky, Hugh J. McMillan (D), James J. Dowling, \\ Reshma Amin, Cynthia Gagnon, Kathryn Selby
}

Keywords: Spinal muscular atrophy, Gene replacement therapy, Onasemnogene

doi:10.1017/cjn.2021.125

Can J Neurol Sci. 2022; 49: 398-401

\section{BACKGROUND}

Spinal muscular atrophy (SMA) is the second most common autosomal recessive disorder in childhood. It is caused by deletions or mutations in the survival motor neuron 1 (SMN1) gene and characterized by degeneration of motor neurons leading to progressive muscle weakness and atrophy. A similar backup gene called survival motor neuron 2 gene (SMN2) acts as a disease modifier, with increasing number of SMN2 copies associated with milder phenotype. ${ }^{1}$

Considerable advances in the last 10 years have led to the development of disease-modifying therapies in SMA which have transformed outcomes. Therapeutic approaches use different mechanisms of action, routes of administration, and dose scheduling. The core treatments are SMN-dependent and include SMN1 gene replacement or SMN2 pre-mRNA splicing modulation. ${ }^{2}$

With all therapies, the highest efficacy is seen when administered pre-symptomatically, prompting the need for SMA newborn screening programs. ${ }^{3}$ Nusinersen was the first drug approved for SMA treatment in Canada in June 2017. It is administered intrathecally at 4 monthly intervals after 4 initial loading doses. Another SMN2 splicing modulator is risdiplam which is administered orally on a daily basis. It was approved by FDA in August 2020 and recently by Health Canada for infants over 2 months of age with no upper age limit. In 2019, the FDA approved the single intravenous (IV) administration of onasemnogene abeparvovec (OA) for patients under the age of 2 years with 5q SMA, irrespective of the SMN2 copy number. The EMA approved OA in 2020 in patients with 5q SMA with a biallelic mutation in the SMN1 gene and a clinical diagnosis of SMA Type 1 and in patients with 5q SMA with a biallelic mutation in the $S M N 1$ gene and up to 3 copies of the SMN2 gene, weighing up to
$21 \mathrm{~kg}$ and removing an upper age limit. In December 2020, Health Canada approved IV OA for pediatric SMA patients with 3 or fewer copies of SMN2 or with infantile-onset SMA, also with no age or weight limit specified.

The clinical trials on $\mathrm{OA}$ included patients under 6 months of age and less than $8.4 \mathrm{~kg}$, and reimbursement recommendations in Canada align with this, limiting access to infants under 6 months of age with 3 copies of SMN2 or less with no permanent ventilation or exclusive enteral feeding (https:// cadth.ca/onasemnogene-abeparvovec). Other than select case series, there is a knowledge gap on its safety and efficacy in older and heavier children as well as those with more advanced disease that would be potentially included in Health Canada's broader label. In order to address these gaps and provide guidance, an ad hoc European group of 13 SMA experts have published a set of consensus statements on the use of gene replacement therapy in SMA, all reaching 100\% agreement among the experts through a Delphi consensus process. ${ }^{4}$ With OA now commercially available to Canadians, we set out to provide guidance adapted to the Canadian context and highlight areas of future needs.

\section{Methods \\ We conducted a cross-sectional survey of clinical experts in SMA across Canada to gauge their agreement on the European ad hoc consensus statements on gene replacement therapy for the Canadian context. The survey participants were identified through the Neuromuscular Disease for Canada (NMD4C) mem- bership, a pan-Canadian network of leading experts working together to improve care, research, and collaboration in}

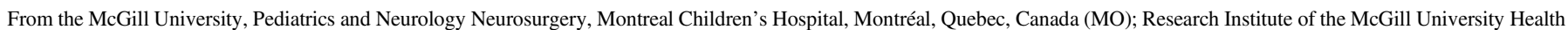

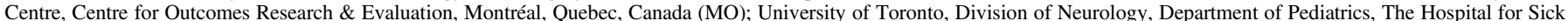

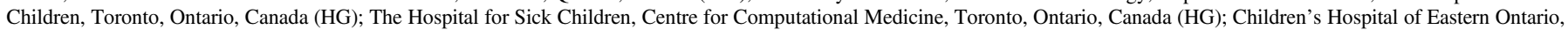

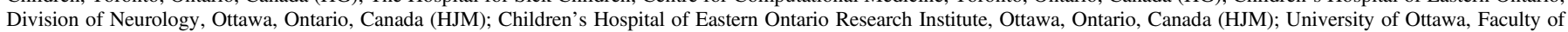

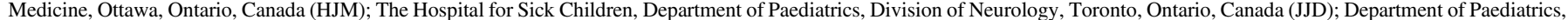

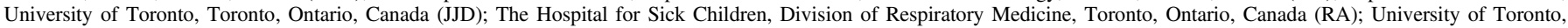

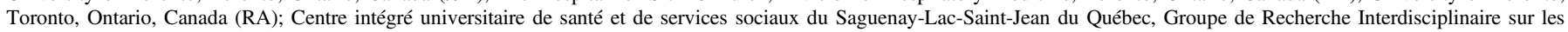

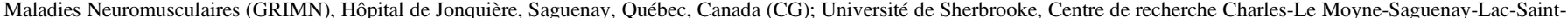

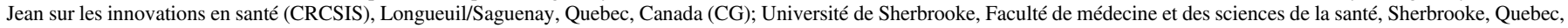
Canada (CG); and The University of British Columbia, Division of Pediatric Neurology, Department of Pediatrics, Vancouver, British Columbia, Canada (KS)

Received March 30, 2021. Final Revisions Submitted May 28, 2021. Date of Acceptance May 31, 2021.

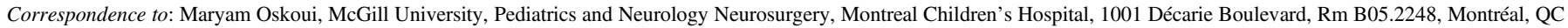
H4A 3J1, Canada. Email: maryam.oskoui@mcgill.ca 
neuromuscular disease. Each statement was voted on anonymously using REDCap electronic data capture tools. For our consensus to be comparable to the European group, we used the same agreement thresholds: a consensus greater than $95 \%$ was considered 'strong consensus', between $75 \%$ and $95 \%$ 'consensus', and between $50 \%$ and $75 \%$ 'majority consensus'. Less than $50 \%$ approval was labeled as 'no consensus'. In addition, experts were asked to identify key issues related to the implementation of gene replacement therapy in the Canadian context.

Differences between participants and nonparticipants were explored using proportions and chi-square analysis on province of practice and Royal College of Physician speciality certification year. Financial conflict of interest among respondents was reported, and association with full agreement of all statements was measured by odds ratio and $95 \%$ confidence interval.

\section{Results}

Surveys were sent to 35 pediatric Canadian SMA experts from the NMD4C membership, with representation from most provinces. Of these, 21 participated in the survey $(60 \%$ response rate). There was no significant difference between participants and nonparticipants in province of practice (chi square 4.33; $\mathrm{p}=0.74$ ) or mean and range of years since obtaining specialty certification by the Royal College of Physicians and Surgeons of Canada (participants mean 16 years, range 4-29 years; nonparticipants mean 20 years, range 4-37 years). Of the participants, $11 / 21$ declared a financial conflict of interest (COI) (52\%) and $9 / 21(43 \%)$ had a financial conflict of interest with Novartis, the sponsor. Of the participants with a financial COI, $82 \%$ agreed with all 14 statements, whereas only $70 \%$ of those without a COI agreed with all statements (OR 1.9, 95\% CI 0.3, 13.0). In comparison, of the 13 European experts, 12 presented a conflict of interest $(92 \%)$ of which all included the sponsor.

The fourteen statements of the original article were explored, of which 13 reached a strong consensus of 95\%-100\% agreement across Canadian experts and one reaching good consensus with $85 \%$ agreement (Table 1 ).

\section{Canadian Perspective}

Several key issues were highlighted by experts regarding treatment response, safety, and efficacy in older or heavier patients, administration and follow-up, and newborn screening program.

Clinical factors can guide our ability to predict treatment response. In presymptomatic patients who have yet to develop clinical symptoms, the SMN2 copy number is the best available predictor of future disease severity. The SMN2 copy number determination is challenging especially when a high copy number is present and should only be carried out by specialized laboratories experienced with this technique. Other potential alternative biomarkers for the clinical course of the disease, such as neurofilaments and electrophysiological biomarkers, have been studied. ${ }^{5}$ In symptomatic patients, the clinical classification of disease into subtypes is not a sufficient predictor of trajectory of the response to treatment, with a wide spectrum and overlap across types. An earlier age of onset predicts a more severe phenotype with likely prenatal loss of motoneurons.
A longer duration of symptoms, lower level of current functioning, and dependence on ventilatory and nutritional support represent more advanced stages of disease where treatment response expected will be smaller. Clinicians should be aware of these factors potentially influencing treatment response and counsel families accordingly.

The clinical trials supporting the safety and efficacy of IV OA included infants under 6 months of age and under $8.4 \mathrm{~kg}$ bodyweight, with only limited observational data beyond this range. Further rigorous clinical trials are needed to establish safety and efficacy in older or heavier patients, and the sponsor has announced a clinical trial of OA in patients weighing $\geq 8.5 \mathrm{~kg}$ and $\leq 21 \mathrm{~kg}$ (NCT04851873). It is essential to establish clear guidelines governing access to gene therapy, based on highquality evidence to ensure that the treatment meets the highest standards of safety and efficacy. A standardized framework for treatment administration until more evidence is available could help meet these standards and override the potential inequity regarding national access to treatment. The recent recommendations by CADTH provide an excellent evidence-based framework, limiting access to infants 6 months of age or younger with three SMN2 copies or less without advanced bulbar symptoms. In all cases, children and their parents should be well informed of all potential side effects and available treatment alternatives.

Administration of gene therapy and follow-up should be carried out by specialized experienced centers. Trained and experienced physical therapists are needed at these sites to perform standardized motor outcome measures specifically validated in this population. As neuromuscular center accreditation is not available in Canada and may jeopardize access to treatment in some regions, identification of the regional expert treatment centers should be made available to ensure equitable access to treatment. The experts all support the need for national data collection to contribute to the growing body of real-world evidence needed to inform care. The Canadian Neuromuscular Disease Registry already implemented across Canada will facilitate this, and data should be owned and queried by academics.

A national strategy for high-cost innovative therapies is critically needed in Canada. As health care is provincially funded, there is significant disparity in access to expensive drugs for rare diseases across the country. It is also essential to demonstrate benefit across the spectrum of disease via appropriate clinical trials with evaluation of long-term outcomes. The cost of treating patients clinically who are on the spectrum outside of demonstrated benefit should be shouldered by the sponsor, who should carry the burden of building evidence of efficacy and most importantly safety of their product.

The earlier any disease-modifying therapy in SMA is introduced, before any clinically apparent, irreversible motor neuron loss occurs, the better the outcome. Early data have shown that infants treated presymptomatically have near normal health outcomes, while infants treated even shortly after symptom onset will have a lifelong physical disability despite treatment. The experts agree that treatment should not be delayed, especially in infants who have a more rapidly degenerative course. If gene therapy is considered and is predicted to be delayed beyond 2 weeks, another disease-modifying therapy should be initiated to maintain motoneurons before gene therapy can be administered. The experts also agree that there is currently no evidence 


\section{Table 1: Consensus statements agreement among Canadian experts}

\begin{tabular}{|c|c|c|}
\hline Consensus statement & Agreement & Strength of consensus \\
\hline $\begin{array}{l}\text { 1.1: Traditional SMA types (e.g. types } 0,1,2,3,4) \text { alone are not sufficient to define patient populations who might } \\
\text { benefit most from gene therapy. }\end{array}$ & $20 / 21(95.2 \%)$ & Strong consensus \\
\hline $\begin{array}{l}\text { 1.2: In symptomatic patients, age at onset, disease duration, and motor function status at the start of treatment } \\
\text { are the most important factors that predict response to treatment. }\end{array}$ & $21 / 21(100 \%)$ & Strong consensus \\
\hline $\begin{array}{l}\text { 2.1: In presymptomatic patients, SMN2 copy number is the most important predictor of clinical severity and age } \\
\text { of onset. }\end{array}$ & $21 / 21(100 \%)$ & Strong consensus \\
\hline $\begin{array}{l}\text { 2.2: As long as no better biomarkers or predictors are available, treatment decisions for presymptomatic patients } \\
\text { should primarily be based on } S M N 2 \text { copy number. }\end{array}$ & $20 / 21(95.2 \%)$ & Strong consensus \\
\hline $\begin{array}{l}\text { 2.3: Determination of } S M N 2 \text { copy number needs to be performed in an expert laboratory with adequate measures } \\
\text { of quality control. }\end{array}$ & $21 / 21(100 \%)$ & Strong consensus \\
\hline $\begin{array}{l}\text { 3: Approval of gene therapy for SMA with Zolgensma }{ }^{\circledR} \text { is based on clinical trials with patients with SMA less than } \\
6 \text { months of age. Additional data of patients up to } 2 \text { years and weighing up to } 13.5 \mathrm{~kg} \text { are made public through } \\
\text { congress presentations. These data mainly come from nonsystematic data collection in the USA, where } \\
\text { Zolgensma }{ }^{\circledR} \text { is approved up to the age of } 2 \text { years. When administered after the age of } 6 \text { months and/or in advanced } \\
\text { stages of the disease, parents or patients should clearly be made aware that there are so far no published data on } \\
\text { efficacy and safety. In this patient population, it is particularly important for physicians to discuss the benefit/risk } \\
\text { ratio and to carefully manage parents' or patients' expectations. }\end{array}$ & $20 / 21(95.2 \%)$ & Strong consensus \\
\hline $\begin{array}{l}\text { 4: In patients presenting with symptoms at birth, treated after a long disease duration, or with already severe } \\
\text { evolution, parents should be clearly made aware that despite the use of gene therapy there is a high risk of living } \\
\text { with a very severe disability. Palliative care should be discussed as an alternative treatment option in these } \\
\text { circumstances. }\end{array}$ & $21 / 21(100 \%)$ & Strong consensus \\
\hline $\begin{array}{l}\text { 5: Since the risk of gene therapy increases with the dose administered and since the dose is directly proportional } \\
\text { with the weight, patients above } 13.5 \mathrm{~kg} \text { should only be treated in specific circumstances. For these patients, } \\
\text { treatment with other disease-modifying therapies or future intrathecal administration of Zolgensma }{ }^{\circledR} \text { should be } \\
\text { considered as an alternative. }\end{array}$ & $20 / 21(95.2 \%)$ & Strong consensus \\
\hline $\begin{array}{l}\text { 6: Until now there is no published evidence that combination of two disease-modifying therapies (e.g. gene therapy } \\
\text { and nusinersen) is superior to any single treatment alone. }\end{array}$ & $20 / 21(95.2 \%)$ & Strong consensus \\
\hline $\begin{array}{l}\text { 7: Centers performing gene therapy for SMA should have broad expertise in the assessment and treatment of } \\
\text { SMA according to international standards. They should also have the ability and resources to deal with potential } \\
\text { side effects of gene therapy. Personnel should be trained and have experience in the use of standardized and } \\
\text { validated outcome measure for SMA to document treatment effects. Recognition as European Reference Centre } \\
\text { (www.ern-euro-nmd.eu) or national accreditation as neuromuscular centre of expertise might serve as additional } \\
\text { selection criteria. }\end{array}$ & $21 / 21(100 \%)$ & Strong consensus \\
\hline $\begin{array}{l}\text { 8: There is convincing evidence that early initiation of treatment ideally in the presymptomatic stage of the disease } \\
\text { is associated with markedly better outcome as compared to later start of treatment. Spinal muscular atrophy is } \\
\text { therefore a good candidate for inclusion in newborn screening programs. In newly diagnosed patients, any delay of } \\
\text { treatment should be avoided. Ideally, the time frame between diagnosis and initiation of a disease-modifying } \\
\text { treatment should be no longer than } 14 \mathrm{~d} \text {. This is particularly important in infants due to the progressive course of the } \\
\text { disease. }\end{array}$ & $21 / 21(100 \%)$ & Strong consensus \\
\hline $\begin{array}{l}\text { 9: Data concerning effectiveness and safety should be collected systematically for all patients treated. Treatment } \\
\text { centers should be provided with adequate resources to perform long-term monitoring of treated patients with } \\
\text { standardized outcome measures. Where available disease-specific registries should be used for data collection } \\
\text { to allow comparison between different treatments. Data analysis should be performed primarily by academic } \\
\text { institutions and networks. }\end{array}$ & $20 / 21(95.2 \%)$ & Strong consensus \\
\hline $\begin{array}{l}\text { 10: On the basis of the currently available data and in light of existing effective treatment alternatives, intravenous } \\
\text { gene replacement therapy with Zolgensma }{ }^{\circledR} \text { for patients with a body weight }>13.5 \mathrm{~kg} \text { should only be performed } \\
\text { under a more rigorous protocol with continuous monitoring of safety and efficacy. This data collection might be } \\
\text { best achieved in a clinical trial setting. }\end{array}$ & $18 / 21(85.7 \%)$ & Consensus \\
\hline $\begin{array}{l}\text { 11: As the use of Zolgensma }{ }^{(B)} \text { will generate additional evidence during the coming years, pharmaceutical industry, } \\
\text { regulators, patient representatives, and academic networks should collaborate to ensure that any new data on } \\
\text { effectiveness and safety are publicly available in an unbiased and timely manner. This growing body of evidence is } \\
\text { indispensable for an improved risk-benefit assessment for future patients and should not be hampered by particular } \\
\text { commercial or academic interests. }\end{array}$ & $21 / 21(100 \%)$ & Strong consensus \\
\hline
\end{tabular}

indicating combination of two disease-modifying therapies is superior to any single treatment alone, and until further evidence is available would not recommend continuing other upregulators of SMN protein production to be continued after gene therapy administration.
Early identification is needed to limit the burden on health. However, a SMA newborn screening program has only been initiated in the province of Ontario (commenced in 2020). The lack of a national newborn screening program brings inequity to Canadian children. Since June 2017 when nusinersen received 
Health Canada approval, children with SMA born in Canada would have potentially benefited from a completely different health trajectory if a newborn screening program had been in place. In 2020, SMA was added to the Ontario newborn screening program, and a health inequity will continue to be present until newborn screening for SMA becomes available to all Canadians.

The recent advances in disease-modifying therapies in SMA are making a significant impact on care and prognosis. Equitable access to evidence-based treatment and to newborn screening across Canada are essential for ensuring the best outcome for patients with SMA.

\section{ACKNOWLEDGMENTS}

The authors would like to thank James Davis and Valerie Gagne-Ouellet from the NMD4C for support with the REDCap survey; Dr. Tarannum Behlim for data analysis, and Homira Osman from Muscular Dystrophy Canada for her critical feedback of our methods.

\section{FuNDING}

NMD4C is funded by CIHR and Muscular Dystrophy Canada. More information on the NMD4C network is available here: https://neuromuscularnetwork.ca/.

\section{Disclosures}

This work was supported by the Neuromuscular Disease Network for Canada (NMD4C), a network funded through a Network Catalyst Grant (NG2 170,044) provided by Canadian Institutes of Health Research and Muscular Dystrophy Canada. James J. Dowling, Reshma Amin, and Cynthia Gagnon have no conflict of interests to declare. Hernan Dario Gonorazky reports receiving payments for consulting fees from UBC, Roche, Biogen, and Novartis. He also reports receiving payment or honoraria for lectures, presentations, speakers bureaus, manuscript writing or educational events from Biogen and Roche. Maryam Oskoui reports grants or contracts as site investigator for SMA trials from Biogen and Roche. Kathryn Selby reports a grant or contract from Biogen as Prinicpal Investigator of clinical trial site for Nusinersen trial, receiving consulting fees as SMA Advisory Board from Biogen and Novartis, receiving payment or honoraria for lectures and educational events from Biogen, and participation on a data safety advisory board for Biogen and Novartis. Hugh J. McMillan reports receiving financial support for research from Roche, consulting fees from Novartis, and participation on data safety advisory board for Novartis.

\section{Statement of Authorship}

All authors conceptualized the manuscript. MO wrote the first draft of the manuscript with input and feedback from all authors. MO, HJM, HG, JJD, and KS were involved in data acquisition. $\mathrm{MO}$ and CG performed the data analysis. All authors were involved in data interpretation, revising, and approving the final version of the manuscript.

\section{REFERENCES}

1. Oskoui M, Darras BT, De Vivo DC. Chapter 1: Spinal muscular atrophy: 125 years later and on the verge of a cure. In: Sumner CJ, Paushkin S, Ko CP, editors. Spinal muscular atrophy. San Diego: Academic Press; 2017, pp. 3-19.

2. Servais L, Baranello G, Scoto M, Daron A, Oskoui M. Therapeutic interventions for spinal muscular atrophy: preclinical and early clinical development opportunities. Expert Opin Investig Drugs. 2021;30:519-27.

3. McMillan HJ, Kernohan KD, Yeh E, et al. Newborn screening for spinal muscular atrophy: Ontario testing and follow-up recommendations. Can J Neurol Sci. 2020:1-8. doi: 10.1017/cjn. 2020.229.

4. Kirschner J, Butoianu N, Goemans N, et al. European ad-hoc consensus statement on gene replacement therapy for spinal muscular atrophy. Eur J Paediatr Neurol. 2020;28:38-43.

5. Kariyawasam DST, D'Silva A, Lin C, Ryan MM, Farrar MA. Biomarkers and the development of a personalized medicine approach in spinal muscular atrophy. Front Neurol. 2019; 10:898. 